\title{
A CALL TO ACTION FOR EQUALITY
}

\author{
It's time for the academic community to convert \\ words into workplace practice and policy, writes Tim Wess
}

Most women leave the academic workforce before they want to, while many others do not progress as far as they could. Those women who have families have to deal with the confounding pressures of academia; developing a profile demands international travel that takes a researcher away from her family. The main measure of researcher success - publications - also reflects on women who take career breaks.

The result, as countless studies and surveys have confirmed, is a workforce that perpetuates the status quo. So even though women embark on science careers in fairly equal numbers to men, senior positions are still held predominately by men.If you think this doesn't apply to your organization, take a moment to consider how many female academics in your workplace are in part-time, fixed-term teaching positions.

Many women fill these roles because it is the only option their organization offered. Most female academics find themselves in workplaces that penalize the career breaks so often necessitated by child-rearing. And although family responsibilities are far more equitably
Michelle Coote, a chemistry professor at the Australian National University, and a member of SAGE initiative. distributed now than in decades past, it is still women, in most cases, who sacrifice the greatest amount of time to take on the task.

It is time for action. Forty universities and research institutes in Australia are on a collective, yet individual, journey toward genderequality in the workforce.

Modelled on the UK's successful Athena SWAN Charter, the Science in Australia Gender Equity (SAGE) initiative will assess universities on their policies and practices to eliminate gender bias.

The road ahead will not be easy. Social and workplace expectations are firmly entrenched, and establishing a modicum of fairness will require significant cultural or organization shifts. Proactive measures will be needed. These could include releasing university timetables at the same time of year that people with child-caring needs can register at kindergarten and limiting meetings to core working hours.

At my institution, Charles Sturt University, we are determined to reverse the trend of female researchers falling into part-time, fixed term teaching jobs. Our first step is introducing small research scholarships for casual staff.

Paying casual staff to do research for a day a week, or giving them seed funding to support projects, means they can retain a balanced research/teaching portfolio; that will help them apply for more substantive research positions later on. The initiative also ensures there is sufficient teaching staff to support the university's needs.

We also need to be genuine about flexible working conditions. If we consider a balance of online learning and face-to-face teaching good for students, that flexibility should also translate to staff. It's all part of embracing a more diverse workforce.

SAGE allows institutions to share their best practices, and encourages them to be daring in their ingenuity.

Some people stand at the edge of an issue, wring their hands and say that only the government can shift employment policy to ensure equity. But there is another way, and we intend to show how it can be done.

Tim Wess is the executive dean of the Faculty of Science at Charles Sturt University in Australia. 